\title{
Comparison of performance and quantitative descriptive analysis sensory profiling and its relationship to consumer liking between the artisanal cheese producers panel and the descriptive trained panel
}

\author{
Emmanuel de Jesús Ramírez-Rivera, ${ }^{*} \dagger$ Pablo Díaz-Rivera, ${ }^{*}$ Lorena Guadalupe Ramón-Canul, $\ddagger$ \\ José Manuel Juárez-Barrientos,§ Jesús Rodríguez-Miranda,§ Erasmo Herman-Lara,§ \\ Witoon Prinyawiwatkul,\# and José Andrés Herrera-Corredorll ${ }^{1}$ \\ ${ }^{*}$ Colegio de Postgraduados, Campus Veracruz, 91690, Veracruz, México \\ †Tecnológico Nacional de México/Instituto Tecnológico Superior de Zongolica-Campus Valle de Orizaba, 94300, Veracruz, México \\ ‡Instituto de Investigaciones sobre Salud Pública. Universidad de la Sierra Sur, Calle Guillermo Rojas Mijangos S/N, \\ Colonia Ciudad Universitaria, C.P. 70800, Miahuatlán de Porfirio Díaz, Oaxaca, México \\ §Instituto Tecnológico de Tuxtepec, 68350, Oaxaca, México \\ \#School of Nutrition and Food Sciences, Louisiana State University Agricultural Center, Baton Rouge 70803 \\ ॥Colegio de Postgraduados, Campus Córdoba, 94946, Veracruz, México
}

ABSTRACT

The aim of this research was to compare the performance and sensory profiling of a panel of artisanal cheese producers against a trained panel and their relationship to consumer liking (external preference mapping). Performance was analyzed statistically at an individual level using the Fisher's test $(F)$ for discrimination, the mean square error for repeatability, and Manhattan plots for visualizing the intra-panel homogeneity. At group level, performance was evaluated using ANOVA. External preference mapping technique was applied to determine the efficiency of each sensory profile. Results showed that the producers panel was discriminant and repetitive with a performance similar to that of the trained panel. Manhattan plots showed that the performance of artisanal cheese producers was more homogeneous than trained panelists. The correlation between sensory profiles $(R v=0.95)$ demonstrated similarities in the generation and use of sensory profiles. The external preference maps generated individually with the profiles of each panel were also similar. Recruiting individuals familiar with the production of artisanal cheeses as panelists is a viable strategy for sensory characterization of artisanal cheeses within their context of origin because their results were similar to those from the trained panel and can be correlated with consumer liking data.

Key words: discrimination, confidence ellipses, Manhattan plot, multivariate multiple factor analysis

Received November 29, 2017.

Accepted March 20, 2018.

${ }^{1}$ Corresponding author: jandreshc@colpos.mx

\section{INTRODUCTION}

Artisanal cheese-making is a way to economically develop the areas where they are produced (RamírezRivera et al., 2017a). According to NASS (2007, 2016), manufacture of Latin American cheeses increased 33 million $\mathrm{kg}$ from 2006 to 2015. The consumption of this food per capita is $20 \mathrm{~kg} / \mathrm{yr}$ in European countries (i.e., Greece, France) and $2.1 \mathrm{~kg} / \mathrm{yr}$ in Latin America (i.e., Mexico; Cervantes-Escoto and Villegas-De Gante, 2014). In Mexico, cheese production contributes significantly to the gross domestic product of the food sector $(18.5 \%)$ and the nation as a whole $(0.06 \%)$. About $9.5 \%$ of the total income was spent on purchasing dairy products, $24 \%$ of which was specifically for cheeses (Cervantes-Escoto and Villegas-de-Gante, 2014). Villegas-De-Gante and Cervantes-Escoto (2011) indicated that Mexico officially has about 1,500 artisanal cheese-making plants that employ approximately 20,000 people a year.

Artisanal cheeses have been present in the diets for decades due to their nutritional benefits (i.e., proteins, lipids, and vitamins) and sensory characteristics (Drake et al., 2009a). However, the development of regions, where manufacturing artisanal cheeses are the basis of their economy, faces several difficulties in the attempt to improve their market penetration and customer engagement, such as competition against low-price cheeses, lack of appropriate technology for processing, lack of a collective brand, lack in homogeneity of final product, and fluctuations in sensory quality (VillegasDe-Gante and Cervantes-Escoto, 2011; Cervantes-Escoto and Villegas-de-Gante, 2014). Particularly, sensory quality and homogeneity of product can be key for the development of an identity of artisanal cheeses from 
different regions. Unfortunately, the establishment of sensory quality monitoring programs using an external trained panel can be expensive and difficult to afford by artisanal cheese manufacturers (Ares and Varela, 2017). Evaluating the performance of artisanal cheesemakers in comparison with a trained panel can enable the cheesemakers to perform the sensometric characterization of their products in their own context and reduce costs.

Sensory profiles of artisanal cheeses have usually been conducted by trained panels in large companies; however, sensory tasks in small-scale industry are minimal or absent (Endrizzi et al., 2013). Studies by Bárcenas et al. (2000) and Drake et al. (2009a) used different sensory panels to generate and compare sensory profiles. However, in those studies the experience and sensory perception of artisanal cheese producers were not considered. Van-Rijswijk et al. (2008) indicated that knowledge about a product and familiarization with it can influence the generation of attributes for sensometric characterization. In this regard RamírezRivera et al. (2017b) also described the influence of cultural background of panel members. Moskowitz (2017) suggested that to have a better understanding of the performance of artisanal cheesemakers it is required to compare them with a descriptive trained panel.

Knowledge about cheese-making combined with training in sensory techniques may help producers improve their performance (in terms of development of product description, use of scale, quantification of intensity, and use of sensory techniques) to score similarly to expert trained panelists (ISO standard 8586-2, ISO, 1994a; Endrizzi et al., 2013; Ramírez-Rivera et al., 2017b). However, for this to be valid, the results of a panel consisting of artisanal cheesemakers must be compared and analyzed in the same way as a trained panel in terms of (1) performance at an individual and a group level; (2) the sensory profiles in the same factorial plane; and (3) the degree of correlation of the sensory profile with data of another nature (i.e., consumer liking, physicochemical, or instrumental). These points allow detection of a lack of precision in the results, disagreements, and the inability to discriminate between products as well as to determine the intrinsic quality of artisanal cheeses (Tomic et al., 2010). Mathematically, validation can be carried out by different statistical tools such as ANOVA and graphical resources (i.e., Manhattan plot; $F$-values; mean square error, MSE) to monitor the performance of a sensory panel (Tomic et al., 2007; Dahl et al., 2008; Tomic et al., 2010). Multivariate multiple factor analysis (MFA) and external preference mapping (PREFMAP) techniques help in the comparison of sensory profiles between panels and an approach to consumer preferences based on a previously generated sensory vocabulary, respectively (Pagès and Husson, 2001; Drake et al., 2009b). The MFA technique equilibrates the influence of each panel when searching for agreement that allows for the comparison among sensory descriptions performed by both panels (Lê-Dien et al., 2008). The PREFMAP technique uses a regression model to describe the relation between each hedonic judgment $(\mathrm{Y})$ and the principal components (X or sensory attributes; Tenenhaus et al., 2005).

For all of the above, the aim of this research was to compare the results of a panel of artisanal cheese producers with those of a trained panel in terms of individual and group performance and sensory profiling, and then complement the study by comparing the PREFMAP generated by both panels.

\section{MATERIALS AND METHODS}

\section{Origin and Preparation of Artisanal Fresh Cheeses}

Fresh cheese samples were obtained from 4 different goat production units (GPU) located in the central mountainous region of the state of Veracruz, Mexico, and that were affiliated with the nonprofit Goat Species Product-System of Veracruz (Sistema Producto Especie Caprino del Estado de Veracruz). Cheeses were prepared according to the procedure indicated by Ramírez-Rivera et al. (2017a) using milk from the Alpine and Saanen goat breeds. One fresh cheese sample was collected from each of the 4 GPU (Coatepec, Cocoatzintla, Perote, and Tatatila). A total of 4 cylindrical pieces $(3 \mathrm{~kg}$ each) for each fresh cheese were sampled and wrapped with plastic shrink-wrap and refrigerated at $4^{\circ} \mathrm{C}$.

\section{Sample Preparation for the Sensory Analysis}

Prior to the analysis, cheeses were kept at $25 \pm$ $2^{\circ} \mathrm{C}$ for $1 \mathrm{~h}$. Each panelist was presented with $20 \mathrm{~g}$ of cheese obtained from the middle of the cheese (pieces of $1.5 \mathrm{~cm}$ diameter and $3 \mathrm{~cm}$ thickness) in $50-\mathrm{mL}$ white plastic cups identified with random 3-digit numbers. Water and unsalted crackers were provided to panelists between samples for palate cleansing (Ramírez-Rivera et al., 2017b).

\section{Sensory Descriptive Panels}

The research protocol was approved by the Technical Committee of the Investment and Management Trust of Colegio de Postgraduados and by the cheesemakers of Sistema Producto Especie Caprino del Estado de Veracruz that participated in the sensory training and evaluation process. Two sensory panels were formed independently. Panel 1 was recruited from the arti- 
sanal cheese producers in the goat cheese-making area (Coatepec City, Veracruz, Mexico) who had more than $3 \mathrm{yr}$ of experience in the production of artisanal goat cheeses (ARTPROP, $\mathrm{n}=7,7$ males, 38-54 yr of age). Panel 2 (TRAINEDP, $\mathrm{n}=6,3$ females and 3 males, 25-32 yr of age) was recruited from subjects who live in Veracruz City, Mexico, who had at least 1 yr of training in the sensory characterization of different commercial and artisanal cheeses (Ramírez-Rivera et al., 2017b). Detailed information about the artisanal goat cheese production process was not revealed to this panel during the study to avoid biases. The panel sizes met ISO standard 11035 (ISO, 1994b), Maximo-Gacula and Rutenbeck (2006), and Drake (2007), which indicate that a sensory panel with 6 to 14 panelists is adequate for descriptive analysis. The selection of subjects and the number of panelists for both the ARTPROP and TRAINEDP panels were conducted according to ISO standard 8586-1 (ISO, 1993) and ISO standard 11035 (ISO, 1994b). The TRAINEDP and ARTPROP were screened in 3 stages (Ramírez-Rivera et al., 2017b). Stage 1 was determination of availability, motivation, and no aversion of the panelists to goat cheese (ISO standard 8586-1: ISO, 1993). Stage 2 included screening of panelists using a basic taste test (sweet, sour, bitter, and salty), aroma recognition test (ISO standard 5496: ISO, 2005), discriminative triangle test (ISO standard 4120: ISO, 2004a), duo-trio test (ISO standard 10399: ISO, 2004b), and texture description test (ISO standard 8586-1: ISO, 1993). Stage 3 was a sequential analysis (ISO standard 16820: ISO, 2004c) that used the test results for panelist selection. The TRAINEDP panel evaluation sessions were conducted at the Sensory Laboratory of Colegio de Postgraduados, in which the testing room was illuminated with cool, natural light-emitting diodes, and evaluations were conducted in separate booths. The ARTPROP sessions were conducted in a conference-type room at the GPU that was equipped with ventilation for elimination of odors, illumination with fluorescent lamps, and a table with dividers for privacy during evaluation. All panelists signed a consent form to participate in the study and were rewarded with a gift basket.

\section{Sensory Descriptive Analysis Procedures}

Sensory profiles for the artisanal goat cheeses was developed by both panels (ARTPROP and TRAINEDP) using the quantitative descriptive analysis method according to ISO standard 11035 (ISO, 1994b) with slight modifications. A 9-cm unstructured linear scale $(0=$ none to $9=$ strong intensity) was used instead of a 15 $\mathrm{cm}$ scale because it is more sensitive than other scales (Stone and Sidel, 2004). Also, due to the time con- straints of the goat cheese producers, consensus (which was achieved in the first 2 sessions) among the panelists (Hernández-Morales et al., 2010; Ramírez-Rivera et al., 2017b) was used for the selection and definition of sensory vocabulary (Table 1 ). Each panel defined their own sensory vocabulary. This information was then used for determining agreement and disagreement among panels (Martin et al., 2000). The ISO standard 11035 (ISO, 1994b) requires conducting several sessions as follows: identification of terms (two 2-h sessions), list of final descriptors (one 1-h session), choice of references (2 sessions of $2 \mathrm{~h}$ ) per descriptor, repeatability test (in duplicate with 2-h intervals between sessions), and use of sensory profiling until the panel has assimilated all the perceptions associated with the descriptors and is able to quantify its perceptions. In sessions 3 through 8 , sensory attributes of cheese samples from different batches and producers were evaluated by the 2 panels. During sessions, each panelist evaluated the sensory attributes in a progressive order (appearance, texture, aroma, mouthfeel, flavor, and aftertaste). Panelists were asked to read the definition of each attribute, evaluate the cheese samples based on the references, and indicate the perceived intensity of the attribute on the scale provided. The cheese samples were served in a sequential monadic manner, following an optimal Latin square experimental design (MacFie et al., 1989; Périnel and Pagès, 2004). Each session (from 3 to 8) lasted 30 to $50 \mathrm{~min}$. Panelists were allowed to rest when necessary.

Commercial fresh goat cheeses from a local supermarket in Veracruz, Mexico, and those suggested by Rainey (1986) were used as references for the study. For this purpose, fresh goat cheeses of the brand Le Fromage, France, and fresh panela-type cheeses of the brand LALA de México S.A. de C.V. were acquired.

\section{Consumer Study}

A consumer study was conducted at the organic products market located in the city of Coatepec, Veracruz, Mexico. Eighty consumers were recruited (38 men and 42 women, between 27 and 54 yr of age) to determine their overall liking for samples of fresh goat cheeses obtained from the different GPU considered in this study. A discrete 9-point hedonic scale, where $1=$ extremely dislike, $5=$ neither like nor dislike, and $9=$ extremely like, was used (Ramírez-Rivera et al., 2017a).

\section{Statistical Analysis}

Data Structure. Statistical analysis for the TRAINEDP panel was conducted with matrices of $(\mathrm{J}$ $\times \mathrm{M} \times \mathrm{I}) \mathrm{K}$, where $\mathrm{J}=4$ cheeses, $\mathrm{M}=2$ sessions, $\mathrm{I}=$ 
Table 1. Sensory vocabularies of fresh cheeses generated by the trained sensory descriptive panel (TRAINEDP) and the panel consisting of experienced artisan cheese producers of goat cheese (ARTPROP) using the quantitative descriptive analysis technique

\begin{tabular}{llll}
\hline & $\begin{array}{c}\text { Attribute } \\
\text { (TRAINEDP) }\end{array}$ & \multicolumn{1}{c}{$\begin{array}{c}\text { Attribute } \\
\text { (ARTPROP) }\end{array}$} \\
\hline White color & Firmness in the mouth & White color & Milk smell \\
Porous surface & Goat aroma & Without holes & Bitter \\
Presence of whey & Milk aroma & Presence of wetness & Acid \\
Firmness to touch & Citrus aroma & Firmness to touch & Fermented aroma \\
Creamy to touch & Whey aftertaste & Gritty to touch & Milk aroma \\
Citrus smell & Milk aftertaste & Sticky to touch & Bitter aftertaste \\
Whey smell & Greasy aftertaste & Greasy to touch & Fermented aftertaste \\
Salty & Goat aftertaste & Acid smell & \\
Acid & & & \\
\hline
\end{tabular}

6 judges, and $\mathrm{K}=17$ attributes for a total of 816 data. Matrices of $\mathrm{J}=4$ cheese, $\mathrm{M}=2$ sessions, $\mathrm{I}=7$ judges, and $\mathrm{K}=15$ attributes were used for the ARTPROP for a total of 840 pieces of data.

Data Analysis Strategy and Outcomes. Sensory data were examined from different perspectives in 4 stages. Stage 1: evaluation of the discriminative power and repeatability of each panelist. Stage 2: evaluation of the discriminative power and repeatability for each panel. Stage 3: searching for agreements and disagreements in the use of sensory vocabulary among panels through a simultaneous representation of sensory profiles. Stage 4: comparison of consumer liking explanation by panel data through the generation of PREFMAP.

\section{Stage 1. Evaluation of Performance by Panelist}

For the evaluation of each panelist's performance, ANOVA with one factor $\left(F_{\text {Product }}\right)$ was applied, using Fisher's test $(F)$ as the discriminant power index and MSE as the repeatability index of the panelist (Tomic et al., 2007). The data of each panelist (i) formed a matrix $(\mathbf{X i})$ of dimensions $(\mathrm{J} \times \mathrm{M}) \times \mathrm{K}$. The number of calculated $F$-values was $\mathrm{I} \times \mathrm{K}=102$ and $\mathrm{I} \times \mathrm{K}=105$ for the TRAINEDP and ARTPROP, respectively. The Manhattan method was used to determine the variability explained in the first 2 principal components (PC) for each attribute per panelist, where a dark color tone indicates that only a small portion of the variance has been explained (Tomic et al., 2010).

\section{Stage 2. Performance Evaluation at the Panel Level}

The following ANOVA model with 3 factors and their interactions was used to determine panel performance:

$$
\mathrm{Y}_{i k s}=\mu+\alpha_{i}+\beta_{k}+\gamma_{s}+\alpha \beta_{i k}+\beta \gamma_{k s}+\alpha \gamma_{i s}+e_{i k s}
$$

where $\mathrm{Y}_{i k s}$ represents the result of a panelist $i$ for the session $s$ in the product $k ; \mu$ is the overall mean; $\alpha_{i}$ is the panelist effect, $\beta_{k}$ is the product effect; $\gamma_{s}$ is the repetition effect; $\alpha \beta_{i k}$ is the product interaction per panelist; $\beta \gamma_{k s}$ is the product interaction per session; $\alpha \gamma_{i s}$ is the panelist interaction per session; and $e_{i j k}$ is the error term of the model with $e_{i k s} \approx N\left(\mathbf{0}, \sigma^{2}\right)$ (Tomic et al., 2007), where $\sigma^{2}$ is the variance. All $F$-tests were obtained using the residual variance as the denominator (Husson et al., 2001).

\section{Stage 3. Comparison and Correlation Between Sensory Profile Maps}

A multi-table MFA technique was applied for the analysis of the representation of the sensory profiles of both panels. Two sensory maps were generated: (1) representing simultaneously both products and sensory panels, and (2) comparing sensory attributes used by each panel (Lê-Dien et al., 2008). Multidimensional discrimination per panel was evaluated by confidence ellipses per product, which contained $95 \%$ of the representations of a product obtained from the generation of virtual panels of judges by randomly resampling 500 times from the actual panels (Cadoret and Husson, 2013). Resampling was performed using data obtained from TRAINEDP [matrices of $(\mathbf{J} \times \mathbf{M} \times \mathbf{I}) \mathbf{K}$, where $\mathbf{J}=4$ cheeses, $\mathbf{M}=2$ sessions, $\mathbf{I}=6$ judges, and $\mathbf{K}$ $=17$ attributes for a total of 816 data points], and ARTPROP [matrices of $(\mathbf{J} \times \mathbf{M} \times \mathbf{I}) \mathbf{K}$, where $\mathbf{J}=$ 4 cheeses, $\mathbf{M}=2$ sessions, $\mathbf{I}=7$ judges, and $\mathbf{K}=15$ attributes for a total of 840 data points]. The $\boldsymbol{R} \boldsymbol{v}$ coefficient was applied to determine the correlation between the generated sensory profiles and consumer liking data (Josse et al., 2008).

\section{Stage 4. Comparison of External Preference Maps}

To determine the relationship of each sensory profile to the consumer liking data, the PREFMAP technique was applied. The PREFMAP were performed in 2 successive steps: step 1 consisted of defining consumer 
classes using the ascending hierarchical classification technique with the Ward method. In step 2, the relationship between the consumer classes (consumer liking data $\mathrm{Y}$ ) and the sensory profile (X) was determined using the following model:

$$
\text { vector model: } Y_{i}=\alpha+\beta_{1} X_{1}+\beta_{2} X_{2}+\varepsilon_{i} \text {, }
$$

where $\mathrm{X}$ and $\mathrm{Y}$ are the coordinates of the cheese in the first and second $\mathrm{PC}$, and $\mathrm{Y}_{\mathrm{i}}$ is the consumer liking result assigned by a consumer class to a cheese. The $\alpha$, $\beta_{1}$, and $\beta_{2}$ are the coefficients of the model, and $\varepsilon_{\mathrm{i}}$ is the error term of the model. Sensory profile efficiency was evaluated by the coefficient of determination $\left(\mathbf{R}^{2}\right)$ per consumer class.

The PREFMAP and $\mathrm{R}^{2}$ tests were conducted with the XLSTAT software, version 2009 (Addinsoft, New York, NY). Manhattan plots were performed with PanelCheck software, version 1.4.2 (Nofima Mat and DTU-Informatics and Mathematical Modeling, Trom$\mathrm{s} \varnothing$, Norway). Analysis of variance, confidence ellipses, MFA, and the $R v$ coefficient were performed with SensoMineR and FactoMineR packages implemented in programming language R v3.2.5 (R Core Team, 2016).

\section{RESULTS AND DISCUSSION}

\section{Stage 1. Performance Evaluation at the Panelist Level}

Figure 1 shows the $F$-values of the panelists of each panel. In this research, $F$-values $\geq 7$ indicated significant discrimination $(P<0.05)$, that is, panelists were able to discriminate the cheeses according to the sensory vocabulary (Tomic et al., 2010). Panelists of the TRAINEDP showed a high discrimination power $(P<$ $0.05)$ in the attributes WHEY-P, FIRM-T, WHEY-S, SALT, ACID, FIRM-M, GOAT-A, MILK-A, CITR-A, WHEY-AF, GREA-AF, and GOAT-AF (Figure 1a), where CITR = citrus; FIRM = firmness; GREA = greasy $\mathbf{S A L T}=$ salty $; \mathbf{A}=$ retronasal aroma; $\mathbf{T}=$ texture by touching; $\mathbf{M}=$ mechanical $/$ masticated in the mouth; $\mathbf{S}=$ smell via a nasal passage; and $\mathbf{A F}=$ aftertaste. Panelists of ARTPROP showed their highest discrimination power $(P<0.05)$ in the attributes WHIT-C, W/EYES, WETN-P, FIRM-T, STIC-T, GRIT-T, MILK-S, BITT, ACID, and FERM-A (Figure 1b), where BITT = bitter; FERM = fermented; GRIT = gritty; STIC $=$ sticky; WHIT $=$ white $\mathbf{W} /$ EYES = without holes; WETN = wetness; and $\mathbf{C}$ $=$ color. High MSE values (Table 2) showed that the panelists of the TRAINEDP exhibited lowest repeatability in the attributes FIRM-T, CREA-T, CITR-S, SALT, ACID, GOAT-A, MILK-A, WHEY-AF, MILK-
AF, GREA-AF, and GOAT-AF, where CREA = creamy. The lowest repeatability (high MSE values) of the ARTPROP panelists was found in the attributes W/EYES, GRIT-T, GREA-T, BITT, FERM-A, and BITT-AF (Table 2). Panelists from both groups met the discrimination and repeatability criteria according to Tomic et al. (2007, 2010), who stated that high Ftest values and low MSE values indicate that judges are discriminative and repetitive, respectively.

The Manhattan plots (Figure 2) showed that all attributes evaluated by the panelists of the TRAINEDP group, with the exception of porous surface (PORS) and FIRM-T, required $2 \mathrm{PC}$ to achieve a high level of cumulative variance ( $>80 \%$; Tomic et al., 2010). In the case of the PORS attribute, panelists P2, P4, and P5 (TRAINEDP) obtained a cumulative explained variance in $\mathrm{PC} 2=59.64,35.72$, and $62.11 \%$, respectively, and differed from the rest of the panelists who obtained a cumulative explained variance ranging from 84.17 to $97.90 \%$ (Figure 2). The small systematic variability of the aforementioned panelists was likely due to the noise contained in their data generated by the differences in sensory perception of the panelists (Dahl et al., 2008). For the FIRM-T attribute, panelists P2, P3, and $\mathrm{P} 5$ showed a cumulative variance of $15.64,35.45$, and $59.17 \%$, respectively, in $\mathrm{PC} 2$ (Figure 2). They required at least 3 to $4 \mathrm{PC}$ to have a cumulative explained variance $>80 \%$, indicating that these panelists evaluated the FIRM-T attribute differently from the rest of panelists in their group (Tomic et al., 2010). The Manhattan plot indicated that ARTPROP panelists (Figure 3) needed $2 \mathrm{PC}$ to explain the cumulative variance of all attributes evaluated. Only panelist P2 required more than $4 \mathrm{PC}$ to have a cumulative variance of $100 \%$ for the BITT-AF attribute, whereas the explained variance for the rest of the panelists ranged from 90.01 to $99.55 \%$.

Results from the Manhattan plots demonstrated that the performance of producers (ARTPROP) was more homogeneous (only one panelist differed from the rest of the panel) compared with the panelists from the TRAINEDP (3 panelists were different from the rest of the panel). The differences found between panelists of the same panel are due to the chemoreception of the panelists that is subjected to the intra-individual variability that generates different results for the same sensory attribute (Thuiller et al., 2015).

\section{Stage 2. Performance Evaluation at the Panel Level}

The performance probability values of the TRAINEDP are shown in Table 3 . The product factor indicated that the panel was highly discriminant $(P<0.0001)$ in the 17 attributes evaluated (100\% effectiveness in discrimi- 

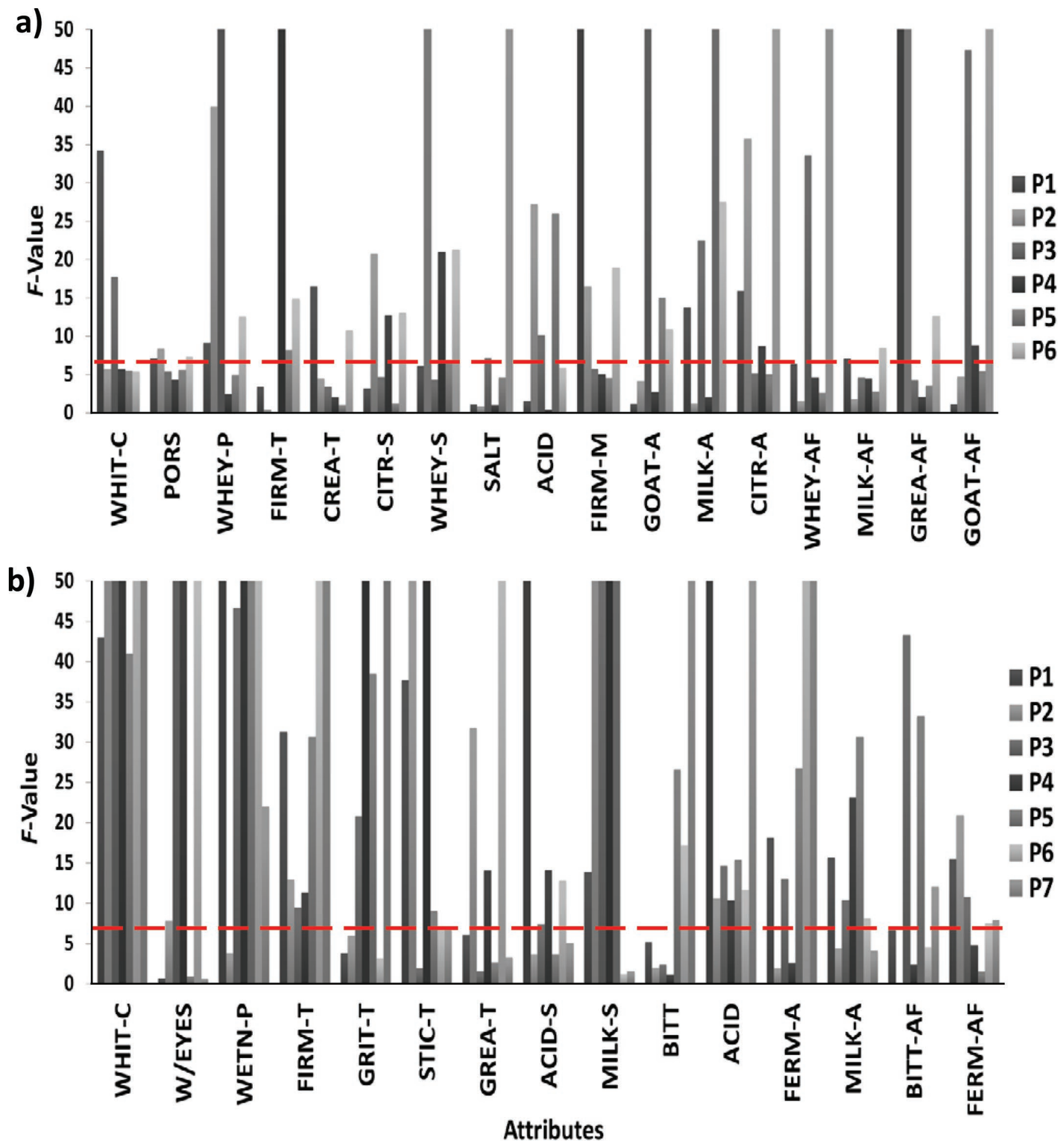

Figure 1. F-test values: panelists (P1 to P7; from left to right within each attribute) from the trained sensory descriptive panel (TRAINEDP; a) and the panel consisting of experienced artisan cheese producers of goat cheese (ARTPROP; b). The dotted horizontal line indicates significant discrimination $(F$-test $\geq 7)$. BITT = bitter; CITR = citrus; CREA = creamy; FERM = fermented; FIRM = firmness; GREA = greasy; GRIT $=$ gritty; PORS $=$ porous surface; SALT $=$ salty; $\mathrm{STIC}=$ sticky; $\mathrm{W} / \mathrm{EYES}=$ without holes; WETN $=$ wetness; WHIT $=$ white. $\mathrm{C}=$ color; $\mathrm{A}=$ retronasal aroma; $\mathrm{T}=$ texture by touching; $\mathrm{M}=$ mechanical $/$ masticated in the mouth; $\mathrm{P}=$ presence of an attribute; $\mathrm{S}=$ smell via a nasal passage; $\mathrm{AF}=$ aftertaste. Color version available online. 
Table 2. Range and mean values for mean square error (MSE) of each sensory attribute evaluated by trained sensory descriptive panel (TRAINEDP) and the panel consisting of experienced artisan cheese producers of goat cheese (ARTPROP) ${ }^{1}$

\begin{tabular}{|c|c|c|c|c|c|}
\hline $\begin{array}{l}\text { Attribute of } \\
\text { TRAINEDP }\end{array}$ & Range & Mean & $\begin{array}{l}\text { Attribute of } \\
\text { ARTPROP }\end{array}$ & Range & Mean \\
\hline WHIT-C & $0.4-3$ & 2.14 & WHIT-C & $0.03-0.31$ & 0.22 \\
\hline PORS & $1.48-3.3$ & 2.21 & W/EYES & $0.11-7.9$ & 2.08 \\
\hline WHEY-P & $0-2.25$ & 1.21 & WETN-P & $0.07-1.57$ & 0.36 \\
\hline FIRM-T & $0.06-16.2$ & 5.44 & FIRM-T & $0.07-1.07$ & 0.46 \\
\hline CREA-T & $0.94-5$ & 2.93 & GRIT-T & $0.01-2.49$ & 0.91 \\
\hline CITR-S & $0.72-11.32$ & 2.95 & STIC-T & $0.01-2.4$ & 0.72 \\
\hline WHEY-S & $0.06-2.9$ & 1.34 & GREA-T & $0.27-4.65$ & 1.32 \\
\hline SALT & $0.04-4.3$ & 3.73 & ACID-S & $0.08-2.54$ & 0.86 \\
\hline ACID & $0.91-4.3$ & 2.79 & MILK-S & $0.01-2.54$ & 0.52 \\
\hline FIRM-M & $0.41-3.43$ & 1.38 & BITT & $0.01-3.11$ & 1.35 \\
\hline GOAT-A & $0.03-6.81$ & 3.23 & ACID & $0.01-1.2$ & 0.50 \\
\hline MILK-A & $0.04-8.8$ & 2.74 & FERM-A & $0.01-2.88$ & 1.09 \\
\hline CITR-A & $0.11-2.06$ & 1.14 & MILK-A & $0.15-1.73$ & 0.80 \\
\hline WHEY-AF & $0-7.8$ & 3.36 & BITT-AF & $0-2.52$ & 0.95 \\
\hline MILK-AF & $0.87-4.8$ & 2.58 & FERM-AF & $0.07-1.54$ & 0.85 \\
\hline GREA-AF & $0.01-4.77$ & 1.47 & & & \\
\hline GOAT-AF & $0.11-4.96$ & 2.71 & & & \\
\hline
\end{tabular}

${ }^{1} \mathrm{MSE}$ values were calculated with ANOVA with one factor $\left(F_{\text {Product }}\right)$. Low or close to 0 MSE values indicate good repeatability of panelists (Tomic et al., 2007, 2010). BITT $=$ bitter; CITR $=$ citrus; CREA $=$ creamy; FERM = fermented; FIRM $=$ firmness; GREA $=$ greasy; GRIT $=$ gritty; PORS $=$ porous surface; SALT = salty; STIC = sticky; W/EYES $=$ without holes; WETN $=$ wetness; $\mathrm{WHIT}=$ white. $\mathrm{C}=$ color; $\mathrm{P}=$ presence of an attribute; $\mathrm{A}=$ retronasal aroma; $\mathrm{T}=$ texture by touching; $\mathrm{M}=$ mechanical $/$ masticated in the mouth; $\mathrm{S}$ $=$ smell via a nasal passage $\mathrm{AF}=$ aftertaste.

nation). Agreements $(P>0.05)$ were also observed among panelists on all attributes except WHIT-C $(P=$ 0.02), WHEY-P $(P<0.0001)$, CITR-A $(P<0.0001)$, MILK-AF $(P=0.03)$, and GREA-AF $(P=0.02)$. The panel was repetitive $(P>0.05)$ in evaluations from one session to another on all attributes except WHEY-P. The product $\times$ panelist interaction showed similarities $(P>0.05)$ in the positioning on the intensity scale in 7 of 17 attributes. The product $\times$ session interaction revealed that the panel generated similar values $(P>$ $0.05)$ between sessions in all attributes. The panelist $\times$ session interaction determined that panelists used the intensity scale between sessions and in all attributes in a similar way $(P>0.05)$. In this regard, the TRAINEDP met the criteria for discrimination $(P<$ 0.05 for product factor $)$ and repeatability $(P>0.05$ for interaction product $\times$ session).

Table 4 shows the performance results of the ARTPROP. This panel was discriminant $(P<0.0001)$ in all evaluated attributes $(100 \%$ effectiveness in discrimination). However, disagreements $(P<0.05)$ were observed among panelists on all attributes. The repetition factor only indicated inconsistency $(P<0.0001)$ in the scores between sessions for the W/EYES and MILK-A attributes. The product $\times$ panelist interaction indicated that no consensus among panelists for all evaluated attributes $(P<0.0001)$, indicating that panelists rated cheeses at different levels of the intensity scale. The product $\times$ session interaction revealed that the panel was consistent $(P>0.05)$ in evaluating all attributes between sessions. The panelist $\times$ session interaction determined that the panelists rated the cheeses similarly $(P>0.05)$ on the intensity scale between sessions, with the exception of W/EYES $(P<0.0001)$. The above results indicate that the ARTPROP adequately meets the criteria of discrimination or differentiation between cheeses (product factor) and repeatability or consistency in the generation of intensity values among sessions (product $\times$ session interaction) considered of greatest interest for the performance of a sensory panel (Tomic et al., 2010; Lê-Dien and Worch, 2015).

\section{Stage 3. Comparison and Correlation Between Sensory Maps}

The confidence ellipses show (1) a clear discrimination of the 4 cheeses evaluated by each panel; (2) the overlapping of the confidence ellipses for the same cheese indicates that both panels perceived the product similarly $(P>0.05)$; and $(3)$ the confidence ellipses of ARTPROP show smaller size (in the Coacoatzintla, Coatepec, and Perote cheeses) compared with the TRAINEDP ellipses. This indicates that the ARTPROP yielded consistent results (Cadoret and Husson, 2013), matching the theory proposed by Solomon (1997) that indicates expert panelists can more precisely dif- 
ferentiate in a category of products; (4) the representations of each panel (partial points) are closed for each cheese (middle point), indicating that all cheeses were characterized in a similar way (Lê-Dien et al., 2008) as observed in the first 2 MFA dimensions of Figure 4a.
In this sense, the same direction was observed in the factorial plane of the following attributes (Figure 4b): MILK-S (ARTPROP) and MILK-AF (TRAINEDP); ACID (TRAINEDP) and ACID-S (ARTPROP); WITH-C (ARTPROP and TRAINEDP); FIRM-T
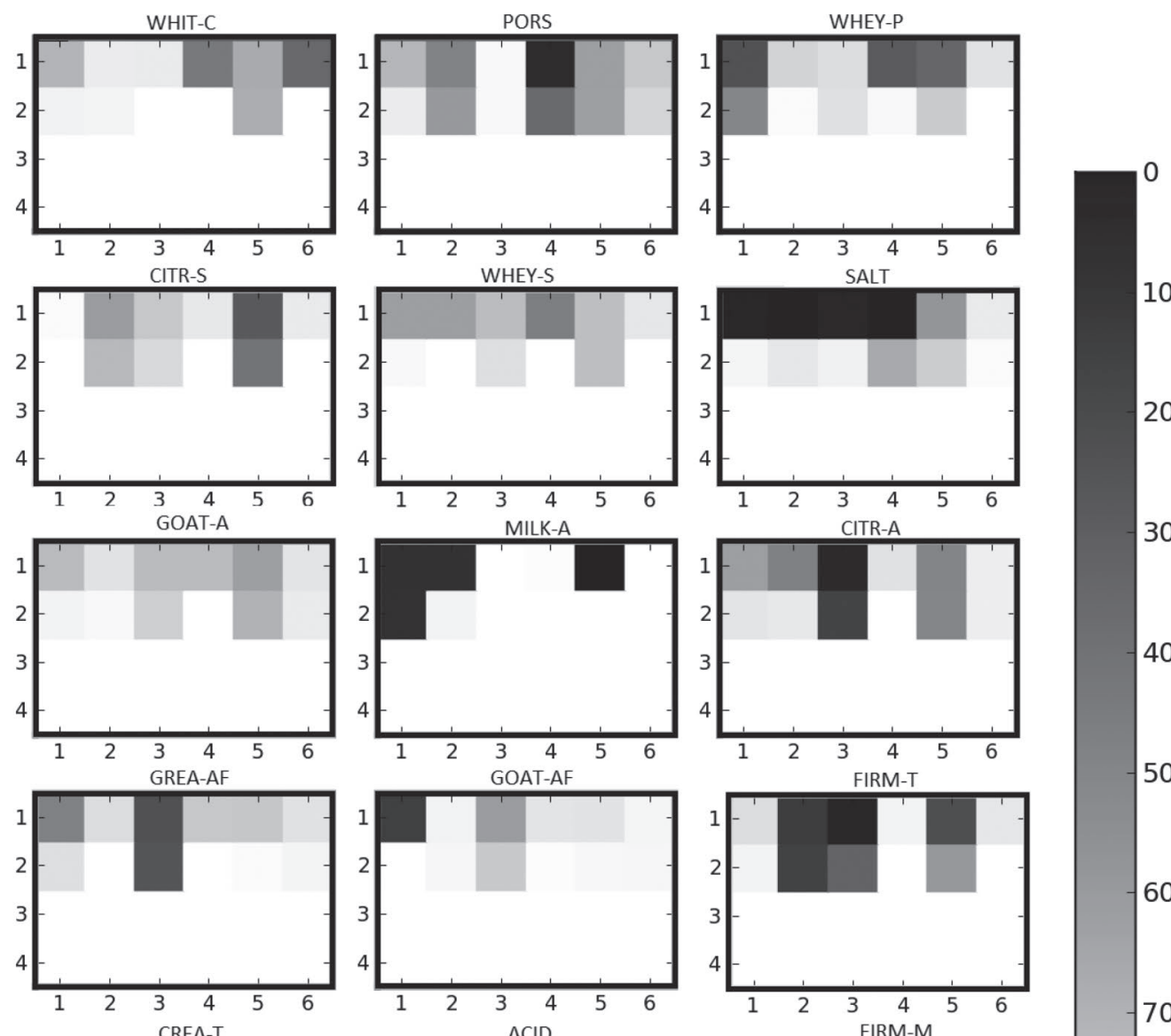

10
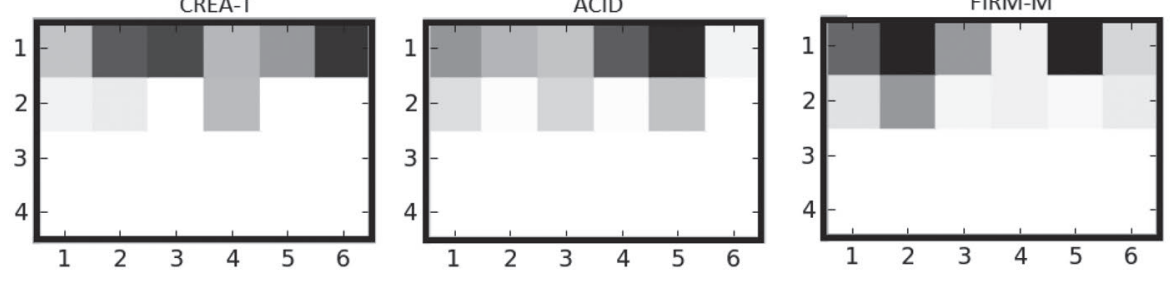

20

30
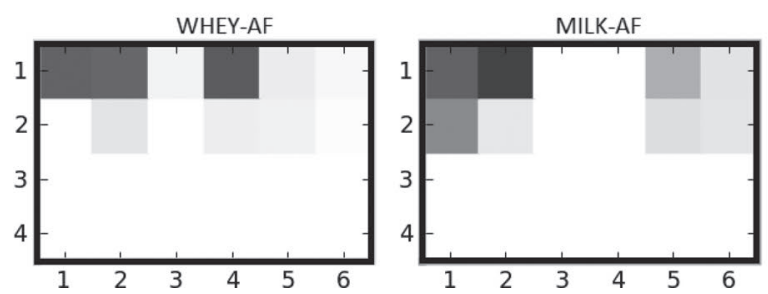

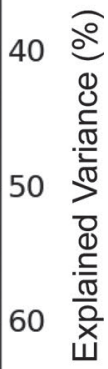

70

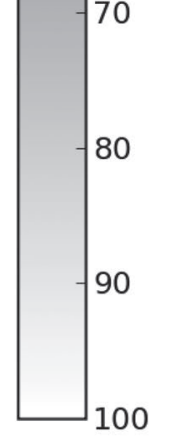

Figure 2. Manhattan plot per sensory attribute of the trained sensory descriptive panel (TRAINEDP). The vertical axis represents the number of principal components (PC). The horizontal axis corresponds to each panelist on the panel. Changes in tone from dark to light indicate high percentages of cumulative explained variance. CITR = citrus; CREA = creamy; FIRM = firmness; GREA = greasy; PORS = porous surface; $\mathrm{SALT}=$ salty; WHIT $=$ white. $\mathrm{C}=$ color; $\mathrm{P}=$ presence of an attribute; $\mathrm{A}=$ retronasal aroma; $\mathrm{T}=$ texture by touching; $\mathrm{M}=$ mechanical/ masticated in the mouth; $\mathrm{S}=$ smell via a nasal passage; $\mathrm{AF}=$ aftertaste. 

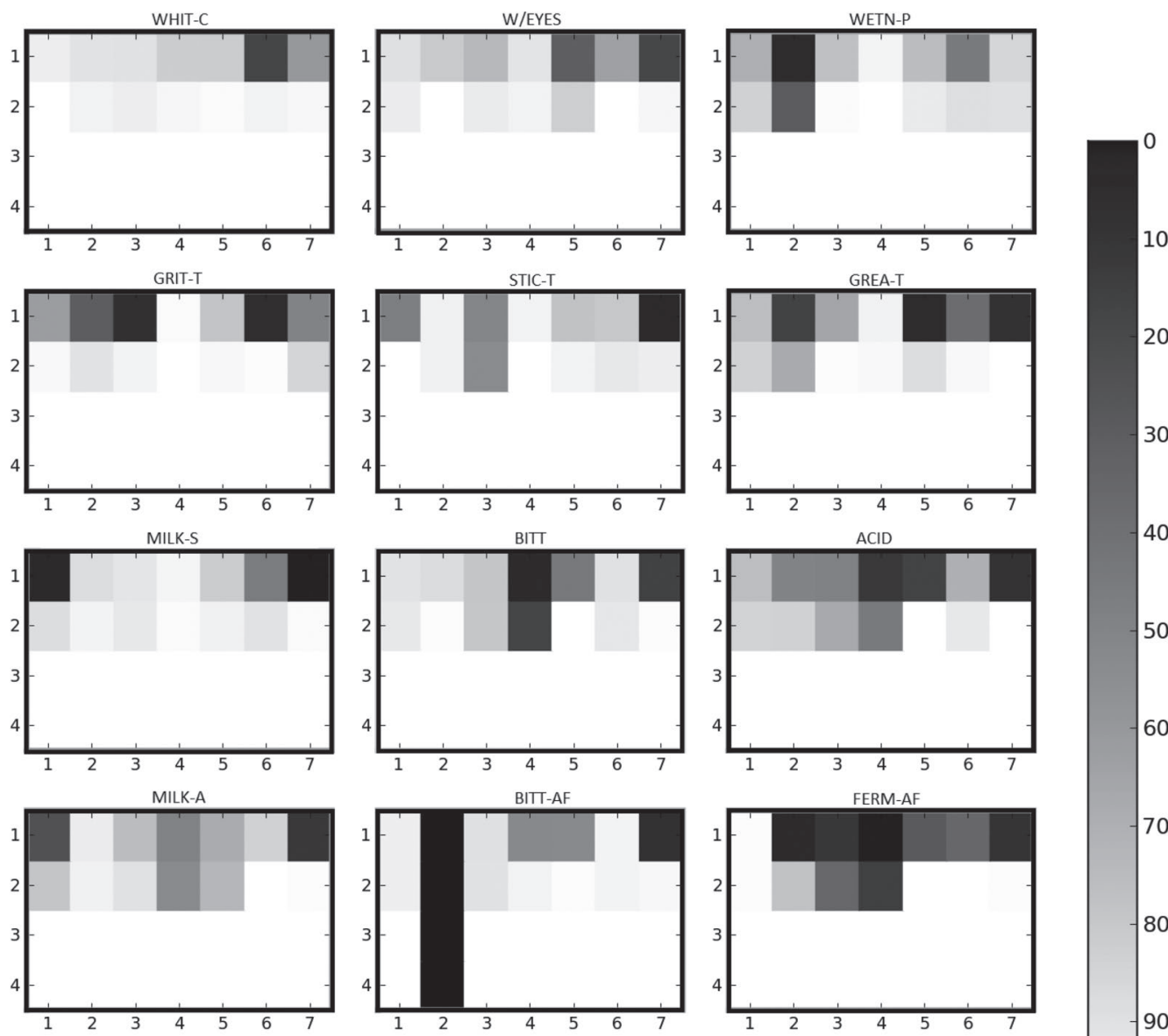

0
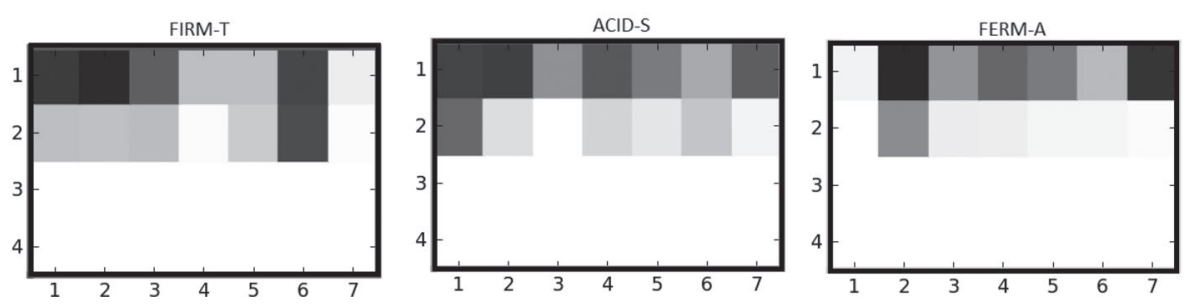

40

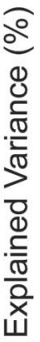

Figure 3. Manhattan plot per sensory attribute of the panel consisting of experienced artisan cheese producers of goat cheese. The vertical axis represents the number of principal components (PC). The horizontal axis corresponds to each panelist on the panel. Changes in tone from dark to light indicate high percentages of cumulative explained variance. BITT $=$ bitter; FERM $=$ fermented; FIRM $=$ firmness; GREA $=$ greasy; GRIT = gritty; $\mathrm{STIC}=$ sticky; W/EYES $=$ without holes; WETN $=$ wetness; WHIT $=$ white. $\mathrm{C}=$ color; $\mathrm{P}=$ presence of an attribute; $\mathrm{A}=$ retronasal aroma; $\mathrm{T}=$ texture by touching; $\mathrm{S}=$ smell via a nasal passage; $\mathrm{AF}=$ aftertaste.

(ARTPROP); FIRM-T and FIRM-M (TRAINEDP); GREA-T (ARTPROP) and GREA-AF (TRAINEDP). This may be due to the training process, which was the same for both panels.

In the same figure one can also see antonymic attributes defined by having opposite directions in the factorial plane (i.e., PORS vs. W/EYES; SALT vs. BITT, BITT-AF, and ACID), as well as related attributes (i.e., PORS generates release of WETN-P, WHEY-S, and WHEY-P; the ratio of ACID present in MILKS, MILK-AF, CITRI-A, and CITRI-S). According to
Ramírez-Rivera et al. (2017b) antonymic attributes can be the result of the differences of perceived intensity and the use of different terms for describing the same sensation. In addition, Ballester et al. (2009) indicated that experts organize their chemosensory knowledge in a network that interrelates a series of sensory attributes. They first identify the cheese as artisanal and then seek for the attributes typically related to the product using their long-term memory (for associating specific sensory attributes they know and consider "must be present"). On the other hand, trained panel- 
Table 3. $P$-values of the 3 -way ANOVA with interactions for the trained sensory descriptive panel

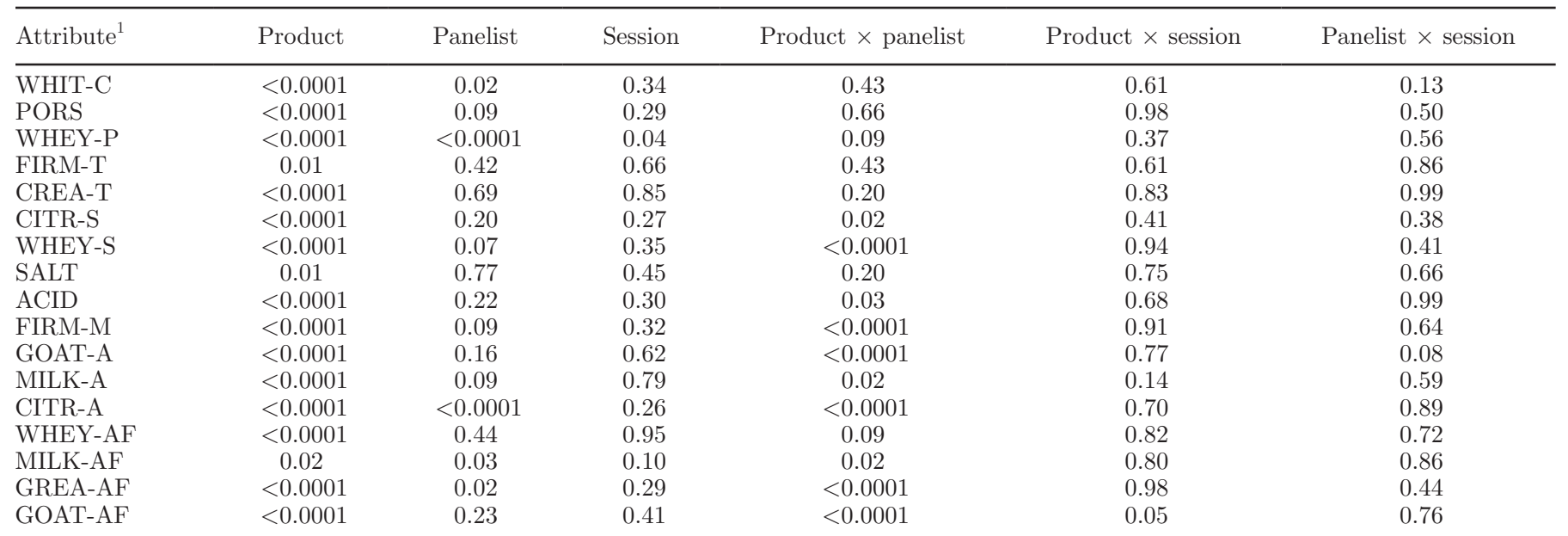

${ }^{1} \mathrm{CITR}=$ citrus; $\mathrm{CREA}=$ creamy; FIRM $=$ firmness; GREA = greasy; PORS = porous surface; SALT = salty; WHIT $=$ white. $\mathrm{C}=$ color; $\mathrm{P}$ $=$ presence of an attribute; $\mathrm{A}=$ retronasal aroma; $\mathrm{T}=$ texture by touching; $\mathrm{M}=$ mechanical $/$ masticated in the mouth; $\mathrm{S}=\mathrm{smell}$ via a nasal passage; $\mathrm{AF}=$ aftertaste.

ists use short-term memory for comparing attributes of a sample against a reference provided during the study (Clara-Zamora and Guirao, 2004).

The MFA results were supported by the significant correlation value $(P<0.05)$ between the sensory profiles $R v_{\text {TRAINEDP-ARTPROP }}=0.95$. This correlation value indicated that the data structure generated by both panels was similar and their evaluations were based on objective and descriptive attributes (Hopfer and Heymann, 2014).

\section{Stage 4. Comparison of External Preference Maps}

Differences $(P<0.05)$ were observed in terms of consumer liking. The Tatatila, Coatepec, Perote, and
Coacoatzintla cheeses obtained overall liking scores of $7.0,6.1,6.0$, and 4.3, respectively, and according to the scores awarded, cheeses are located in the "like moderately" to "dislike slightly" region of the hedonic scale. Using the ascending hierarchical classification technique, consumers were regrouped (class $1=26$, class $2=11$, class $3=24$, and class $4=19$ ) according to their consumer liking scores. The PREFMAP adjusted by a vector model and generated with the descriptive data of the TRAINEDP and ARTPROP are shown in Figure $5 \mathrm{a}, \mathrm{b}$, respectively. The PREFMAP show that classes 3 (30\% of consumers), 1 and 2 (46.25\% of consumers) are located in the 80 to $100 \%$ liking region and that they liked the Tatatila and Perote cheeses, respectively. According to the TRAINEDP sensory profile,

Table 4. $P$-values of the 3-way ANOVA with interactions for the panel consisting of experienced artisan cheese producers of goat cheese

\begin{tabular}{|c|c|c|c|c|c|c|}
\hline Attribute $^{1}$ & Product & Panelist & Session & Product $\times$ panelist & Product $\times$ session & Panelist $\times$ session \\
\hline W/EYES & $<0.0001$ & $<0.0001$ & $<0.0001$ & $<0.0001$ & 0.05 & $<0.0001$ \\
\hline GRIT-T & $<0.0001$ & $<0.0001$ & 0.40 & $<0.0001$ & 0.22 & 0.77 \\
\hline STIC-T & $<0.0001$ & $<0.0001$ & 0.87 & $<0.0001$ & 0.97 & 0.86 \\
\hline GREA-T & $<0.0001$ & 0.02 & 0.22 & $<0.0001$ & 0.47 & 0.60 \\
\hline BITT & $<0.0001$ & $<0.0001$ & 0.87 & 0.03 & 0.29 & 0.82 \\
\hline ACID & $<0.0001$ & $<0.0001$ & 0.39 & $<0.0001$ & 0.70 & 0.91 \\
\hline FERM-A & $<0.0001$ & $<0.0001$ & 0.35 & $<0.0001$ & 0.80 & 0.89 \\
\hline MILK-A & $<0.0001$ & $<0.0001$ & 0.02 & $<0.0001$ & 0.88 & 0.56 \\
\hline BITT-AF & $<0.0001$ & $<0.0001$ & 0.67 & $<0.0001$ & 0.78 & 0.79 \\
\hline FERM-AF & 0.01 & $<0.0001$ & 0.57 & $<0.0001$ & 0.72 & 0.50 \\
\hline
\end{tabular}

${ }^{1}$ BITT $=$ bitter; FERM $=$ fermented; FIRM = firmness; GREA = greasy; GRIT = gritty; STIC = sticky; W/EYES = without holes; WETN = wetness; WHIT $=$ white. $\mathrm{C}=$ color; $\mathrm{P}=$ presence of an attribute; $\mathrm{A}=$ retronasal aroma; $\mathrm{T}=$ texture by touching; $\mathrm{S}=$ smell via a nasal passage; $\mathrm{AF}=$ aftertaste. 

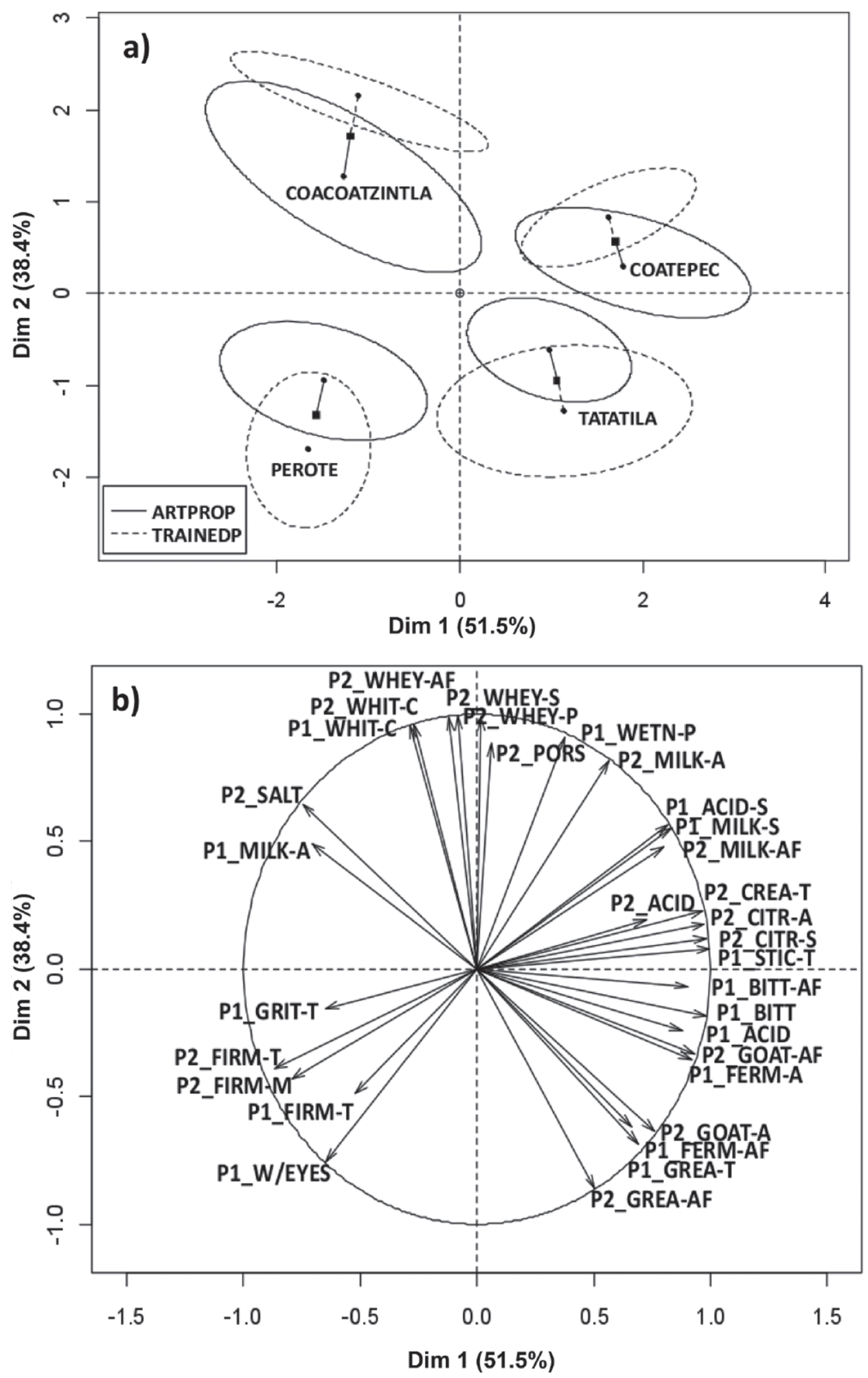

Figure 4. (a) Confidence ellipses associated with each panel and 4 cheeses and (b) direction of sensory attributes per panel in the first 2 principal components of the multivariate multiple factor analysis. $\mathrm{P} 1=$ panel of experienced artisanal goat cheese producers $(\mathrm{ARTPROP})$; $2=$ trained sensory descriptive panel (TRAINEDP). Overlapping confidence ellipses between panels for each cheese indicate similar sensory profiles. $\mathrm{BITT}=$ bitter; CITR = citrus; CREA = creamy; FERM = fermented; FIRM = firmness; GREA $=$ greasy; GRIT $=$ gritty; PORS $=$ porous surface; SALT = salty; STIC = sticky; W/EYES = without holes; WETN $=$ wetness; WHIT $=$ white. $\mathrm{C}=$ color; $\mathrm{P}=$ presence of an attribute; $\mathrm{A}=$ retronasal aroma; $\mathrm{T}=$ texture by touching; $\mathrm{M}=$ mechanical $/$ masticated in the mouth; $\mathrm{S}=$ smell via a nasal passage; $\mathrm{AF}=$ aftertaste. Dim $=$ dimension . 
Tatatila cheese was liked because it had higher GREAAF, GOAT-A, and GOAT-AF intensities, whereas the ARTPROP sensory profile indicated that the same cheese had high BITT, ACID, FERM-A, FERM-AF, and GREA-T intensities. In the case of Perote cheese, the TRAINEDP sensory profile shows that this product was characterized by FIRM-T and FIRM-M. From the point of view of the ARTPROP, this same cheese has W/EYES, GRIT-T, and FIRM-T characteristics. Consumer class number 4 (23.75\% of consumers) liked cheese with high CREA-T, CITR-S, ACID, CITR-A, MILK-A, and MILK-AF intensities according to the TRAINEDP sensory profile and the GREA-T, ACID, MILK-S, and BITT-AF attributes according to the ARTPROP sensory profile. All attributes mentioned above are consistent with the research of Ryffel et al. (2008) who determined that these sensory attributes are one of the reasons behind consumer preference for goat cheeses.

The $\mathrm{R}^{2}$ values showed that the descriptive data $(\mathrm{X})$ of both sensory panels had a greater relationship with the consumer liking data (Y) of classes 3 and 4 (Table 5). According to Hopfer and Heymann (2014), expert panelists (i.e., cheese manufacturers, consultants, cheese masters, and other cheese professionals) have better abilities for discrimination and vocabulary to communicate what they perceive because they use a combination of descriptive and hedonic attributes for cheese characterization. At a global level, $R v$ correlation values $(P<0.05)$ were similar for both panels $\left(R v_{\text {consumer liking-TRAINEDP }}=0.94\right.$ and $R v_{\text {consumer liking-ARTPROP }}$ $=0.87$, respectively), as was the proximity between the 3 groups of variables (consumer liking, TRAINEDP, and ARTPROP) shown in Figure 5C.

The advantages of using artisanal cheese producers are that they have knowledge about the product; fewer economic resources are required because there is no need to hire external panelists; the product evaluation sessions can be routinely conducted at the actual facili-

Table 5. Coefficient of determination $\left(\mathrm{R}^{2}\right)$ values for evaluating the relationship between consumer liking $(\mathrm{Y})$ and descriptive $(\mathrm{X})$ data of each sensory panel ${ }^{1}$

\begin{tabular}{lccc}
\hline & Consumers & $\mathrm{R}^{2}$ & $\mathrm{R}^{2}$ \\
Class $^{2}$ & per class (n) & (TRAINEDP: & (ARTPROP: \\
\hline 1 & 26 & 0.28 & 0.19 \\
2 & 11 & 0.62 & 0.69 \\
3 & 24 & 0.99 & 0.98 \\
4 & 19 & 0.98 & 0.97 \\
\hline
\end{tabular}

${ }^{1}$ TRAINEDP $=$ a trained sensory descriptive panel; ARTPROP $=\mathrm{a}$ panel consisting of experienced artisan cheese producers of goat cheese. ${ }^{2}$ The number of consumers of each class was obtained by the ascending hierarchical classification based on similarity of their liking values.
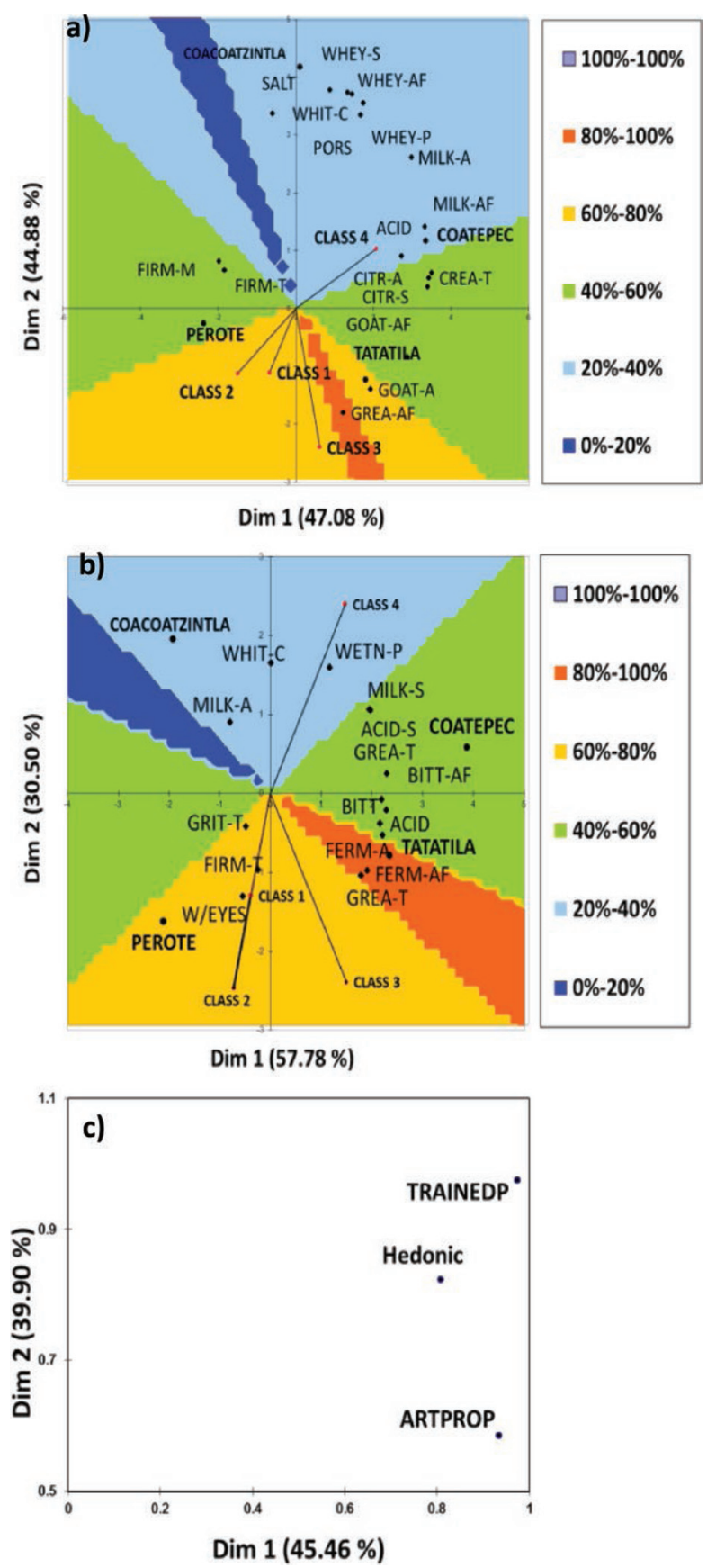

Figure 5. External preference mapping with trained sensory descriptive panel (TRAINEDP) data (a). External preference mapping with data from a panel consisting of experienced artisanal goat cheese producers (ARTPROP; b). Representation of active groups (panels) and consumer liking data via multivariate multiple factor analysis (c). The percentage ranges indicate the proportion of consumers who evaluated the artisanal cheeses. BITT $=$ bitter; CITR $=$ citrus; CREA = creamy; FERM = fermented; FIRM = firmness; GREA = greasy; GRIT = gritty; PORS $=$ porous surface; SALT = salty; STIC = sticky; W/EYES = without holes; WETN = wetness; WHIT $=$ white. $\mathrm{C}=$ color; $\mathrm{P}=$ presence of an attribute; $\mathrm{A}=$ retronasal aroma; $\mathrm{T}=$ texture by touching; $\mathrm{M}=$ mechanical/masticated in the mouth; $\mathrm{S}=$ smell via a nasal passage; $\mathrm{AF}=$ aftertaste. Coatepec, Cocoatzintla, Perote, and Tatatila are different goat production units. Dim $=$ dimension. Color version available online. 
ties of the artisanal cheese manufacturers, facilitating the evaluation of the product right after the processing or during storage; and profits may increase with improved sensory quality (Endrizzi et al., 2013). However, limitations on the use of producer panels are related to time availability and consistency in carrying out the tasting sessions. In addition, it is important to conduct other studies involving the association of the sensory profiles generated by artisanal cheese producers with analytical (i.e., physicochemical, instrumental) data. For a complex food such as cheese, evaluating the panel performance of artisanal producers using other sensory techniques may be necessary. These techniques may include tools for analyzing data focused on each panelist, rapid sensory profiling, and real-time analysis of sensory attributes (Thuiller et al., 2015; RamírezRivera et al., 2017b).

Sensory science is in constant evolution. It was traditionally accepted that only trained assessors were able to provide reliable and replicable sensory descriptive data (Labbe, 2017). However, Ares and Varela (2017) provided evidence for the appropriateness of consumer panels for analytical tasks and cost efficiency. Similarly, recruiting subjects familiar with the products for a sensory descriptive panel is usually avoided as they seem to introduce biases. However, results from in this study indicate that artisan cheese makers can perform similarly to trained assessors in sensory description tasks as long as they receive similar and adequate training.

This paper shows the positive potential of a sensory panel composed of artisanal cheese producers familiar with the manufacture and source knowledge of their cheeses. The results of this panel are similar to those obtained from a trained sensory panel. Additionally, panel implementation can be performed with reduced economic resources and facilities. Therefore, this type of sensory panel is a viable alternative for the sensometric characterization of some artisanal cheeses in their context of origin.

\section{CONCLUSIONS}

The sensory profile of the producers panel characterized the artisanal cheeses in a similar way to the trained panel and an adequate correlation between the profiles was also shown. This demonstrated that the performance of the artisanal cheese producers panel in the aspects of discrimination and repeatability at an individual and a group level is similar to a panel trained under sensory laboratory conditions. This indicates that the producer panel can be used for the sensometric characterization of artisanal cheeses. The PREFMAP generated with the profiles of each panel and the consumer liking data similarly explained the liking of 2 consumer classes based on the sensory profile. For all of the above, a panel of artisanal cheesemakers is a useful and reliable alternative to characterize artisanal cheeses in their context of origin that can help the cheese industry in defining sensory profiles of artisanal goat cheese for further large-scale production.

\section{ACKNOWLEDGMENTS}

The authors are grateful to the Investment and Management Trust No. 167304 (Fideicomiso de Administración e Inversión No. 167304, Colegio de Postgraduados, Montecillo, Estado de México, Mexico) and cheesemakers of Sistema Producto Especie Caprino del Estado de Veracruz (Mexico) for their participation in the study. The authors declare no conflict of interest.

\section{REFERENCES}

Ares, G., and P. Varela. 2017. Trained vs. consumer panels for analytical testing: Fueling a long lasting debate in the field. Food Qual. Prefer. 61:79-86. https://doi.org/10.1016/j.foodqual.2016.10.006.

Ballester, J., H. Abdi, J. Langlios, D. Peyron, and D. Valentin. 2009. The odor of colors: Can wine experts and novice distinguish the odors of white, red, and rosé wines? Chem. Percept. 2:203-213. https://doi.org/10.1007/s12078-009-9058-0.

Bárcenas, P., J. Pérez, and M. Albisu. 2000. Selection and screening of a descriptive panel for ewes milk cheese sensory profiling. J. Sens. Stud. 15:79-99. https://doi.org/10.1111/j.1745-459X.2000 .tb00411.x.

Cadoret, M., and F. Husson. 2013. Construction and evaluation of confidence ellipses applied at sensory data. Food Qual. Prefer. 28:106-115. https://doi.org/10.1016/j.foodqual.2012.09.005.

Cervantes-Escoto, F., and A. Villegas de Gante. 2014. La leche y los quesos artesanales en México. AS y D 11:243-248.

Clara-Zamora, M., and M. Guirao. 2004. Performance comparison between trained assessors and wine experts using specific sensory attributes. J. Sens. Stud. 19:530-545. https://doi.org/10.1111/j.1745 -459X.2004.051404.x.

Dahl, T., O. Tomic, J. P. Wold, and T. Næs. 2008. Some new tools for visualizing multi-way sensory data. Food Qual. Prefer. 19:103-113. https://doi.org/10.1016/j.foodqual.2007.07.001.

Drake, M. A. 2007. Sensory analysis of dairy foods. J. Dairy Sci. 90:4925-4937. https://doi.org/10.3168/jds.2007-0332.

Drake, S. L., K. Lopetcharat, S. Clark, H. S. Kwak, S. Y. Lee, and M. A. Drake. 2009b. Mapping differences in consumer perception of sharp cheddar cheese in the United States. J. Food Sci. 74:S276S285. https://doi.org/10.1111/j.1750-3841.2009.01219.x.

Drake, S. L., K. Lopetcharat, and M. A. Drake. 2009a. Comparison of two methods to explore consumer preferences for cottage cheese. J. Dairy Sci. 92:5883-5897. https://doi.org/10.3168/jds.2009-2389.

Endrizzi, I., E. Aprea, F. Biasioli, M. L. Corollaro, M. L. Demattè, M. Penasa, G. Bittante, and F. Gasperi. 2013. Implementing sensory analysis principles in the quality control of PDO products: A critical evaluation of a real-world case study. J. Sens. Stud. 28:14-24. https://doi.org/10.1111/joss.12018.

Hernández-Morales, C., A. Hernández-Montes, E. Aguirre-Mandujano, and A. Villegas de Gante. 2010. Physicochemical, microbiological, textural and sensory characterization of Mexican Añejo cheese. Int. J. Dairy Technol. 63:552-560. https://doi.org/10.1111/j.1471 $-0307.2010 .00615 . x$.

Hopfer, H., and H. Heymann. 2014. Judging wine quality: Do we need experts, consumers or trained panelists? Food Qual. Prefer. 32:221-233. https://doi.org/10.1016/j.foodqual.2013.10.004. 
Husson, F., S. Lê-Dien, and J. Pagès. 2001. Which value can be granted to sensory profiles given by consumers? Methodology and results. Food Qual. Prefer. 12:291-296. https://doi.org/10.1016/ S0950-3293(01)00014-3.

ISO (International Organization for Standardization). 1993. ISO 8586-1: Sensory Analysis-General Guidance for the Selection, Training, and Monitoring of Assessors, Part 1-Selected assessors. ISO, Geneva, Switzerland.

ISO (International Organization for Standardization). 1994a. ISO 8586-2: Sensory analysis-General guidance for the selection, training and monitoring of assessors-Part 2: Experts. ISO, Geneva, Switzerland.

ISO (International Organization for Standardization). 1994b. ISO 11035: Sensory analysis-Identification and selection of descriptors for establishing a sensory profile by a multidimensional approach. ISO, Geneva, Switzerland.

ISO (International Organization for Standardization). 2004a. ISO 4120: Sensory analysis-Methodology-Triangle test. ISO, Geneva, Switzerland.

ISO (International Organization for Standardization). 2004b. ISO 10399: Sensory analysis-Methodology-Duo-trio test. ISO, Geneva, Switzerland.

ISO (International Organization for Standardization). 2004c. ISO 16820: Sensory analysis-Methodology-Sequential analysis. ISO, Geneva, Switzerland.

ISO (International Organization for Standardization). 2005. ISO 5496: Sensory analysis-Methodology-Initiation and training of assessors in the detection and recognition of odors. ISO, Geneva, Switzerland.

Josse, J., J. Pagés, and F. Husson. 2008. Testing the significance of the RV coefficient. Comput. Stat. Data Anal. 53:82-91. https:// doi.org/10.1016/j.csda.2008.06.012.

Labbe, D. 2017. Commentary on Ares and Varela paper for Food Quality and Preference. Food Qual. Prefer. 61:92-93. https://doi .org/10.1016/j.foodqual.2017.01.012.

Lê-Dien, S., J. Pagés, and F. Husson. 2008. Methodology for the comparison of sensory profiles provided by several panels: Application to a cross-cultural study. Food Qual. Prefer. 19:179-184. https:// doi.org/10.1016/j.foodqual.2007.04.008.

Lê-Dien, S., and T. Worch. 2015. Quantitative descriptive approaches Pages 1-32 in Analyzing sensory data with R. M. J. Chambers, T. Hothorn, D. Temple-Lang, and H. Wickham, ed. Taylor \& Francis Group, CRC Press, New York, NY.

MacFie, H. J., N. Bratchell, K. Greenhoff, and L. V. Vallis. 1989. Designs to balance the effect of order of presentation and first-order carry-over effects in hall tests. J. Sens. Stud. 4:129-148. https:// doi.org/10.1111/j.1745-459X.1989.tb00463.x.

Martin, N., P. Molimard, H. E. Spinnler, and P. Schlich. 2000. Comparison of odour sensory profile performed by two independent trained panels following the same descriptive analysis procedures. Food Qual. Prefer. 11:487-495. https://doi.org/10.1016/S0950 $-3293(00) 00021-5$.

Maximo-Gacula, J. R., and S. Rutenbeck. 2006. Sample size in consumer test and descriptive analysis. J. Sens. Stud. 21:129-145. https://doi.org/10.1111/j.1745-459X.2006.00055.x.

Moskowitz, H. R. 2017. Consumer vs experts: Opinions by an outspoken psychophysicist. Food Qual. Prefer. 61:89-91. https://doi.org/ 10.1016/j.foodqual.2017.01.010.

NASS (National Agricultural Statistics Service). 2007. Dairy products 2006 summary. Accessed Jan 01, 2016. http://usda.mannlib
.cornell.edu/usda/nass/DairProdSu/2000s/2007/DairProdSu-04 -27-2007.pdf

NASS (National Agricultural Statistics Service). 2016. Dairy products 2015 summary. Accessed Jan 01, 2016. http://usda.mannlib .cornell.edu/usda/current/DairProdSu/DairProdSu-04-28-2016 .pdf.

Pagès, J., and F. Husson. 2001. Inter-laboratory comparison of sensory profiles: Methodology and results. Food Qual. Prefer. 12:297-309. https://doi.org/10.1016/S0950-3293(01)00015-5.

Périnel, E., and J. Pagès. 2004. Optimal nested cross-over designs in sensory analysis. Food Qual. Prefer. 15:439-446. https://doi.org/ 10.1016/j.foodqual.2003.07.004

R Core Team. 2016. R: A language and environment for statistical computing. R Foundation for Statistical Computing, Vienna, Austria. www.R-project.org.

Rainey, B. A. 1986. Importance of references standards in training panelists. J. Sens. Stud. 1:149-154. https://doi.org/10.1111/j.1745 -459X.1986.tb00167.x.

Ramírez-Rivera, E. J., J. M. Juárez-Barrientos, J. Rodríguez-Miranda, P. Díaz-Rivera, L. G. Ramón-Canul, J. A. Herrera-Corredor, M. I. Hernández-Serrano, and E. Herman-Lara. 2017a. Typification of a goat fresh cheese of Mexico by path models. Turk. J. Vet. Anim. Sci. 41:213-220. https://doi.org/10.3906/vet-1605-66.

Ramírez-Rivera, E. J., L. G. Ramón-Canul, P. Díaz-Rivera, J. M. Juárez-Barrientos, E. Herman-Lara, W. Prinyawiwatkul, and J. A. Herrera-Corredor. 2017b. Sensory profiles of artisan goat cheeses as influenced by the cultural context and the type of panel. Int. J. Food Sci. Technol. 52:1789-1800. https://doi.org/10.1111/ijfs .13452 .

Ryffel, S., P. Piccinali, and U. Bütikofer. 2008. Sensory descriptive analysis and consumer acceptability of selected Swiss goat and sheep cheese. Small Rumin. Res. 79:80-86. https://doi.org/10 .1016/j.smallrumres.2008.07.006.

Solomon, G. E. A. 1997. Conceptual change and wine expertise. J. Learn. Sci. 1:41-60. https://doi.org/10.1207/s15327809jls0601_3.

Stone, H., and J. L. Sidel. 2004. Measurement. Pages 69-98 in Sensory Evaluation Practices. H. Stone and J. L. Sidel, ed. Elsevier, Academic Press, CA.

Tenenhaus, M., J. Pagès, L. Ambroisine, and C. Guinot. 2005. PLS methodology to study relationships between hedonic judgements and product characteristics. Food Qual. Prefer. 16:315-325. https://doi.org/10.1016/j.foodqual.2004.05.01.

Thuiller, B., D. Valentin, R. Marchal, and C. Dacremont. 2015. Pivot ${ }^{\circledR}$ profile: A new descriptive method based on free description. Food Qual. Prefer. 42:66-67. https://doi.org/10.1016/j.foodqual.2015 .01 .012 .

Tomic, O., G. Luciano, A. Nilsen, G. Hyldig, K. Lorensen, and T. Naes. 2010. Analyzing sensory panel performance in a proficiency test using the PanelCHECK software. Eur. Food Res. Technol 230:497-511. https://doi.org/10.1007/s00217-009-1185-y.

Tomic, O., A. Nilsen, M. Martens, and T. Naes. 2007. Visualization of sensory profiling data for performance monitoring. Lebensm. Wiss. Technol. 40:262-269. https://doi.org/10.1016/j.lwt.2005.09.014.

Van-Rijswijk, W., J. Frewer-Lynn, D. Menozzi, and G. Faioli. 2008. Consumer perception of traceability: a cross-national comparison of the associated benefits. Food Qual. Prefer. 19:452-464. https:// doi.org/10.1016/j.foodqual.2008.02.001.

Villegas de Gante, A., and F. Cervantes-Escoto. 2011. La genuinidad y tipicidad en la revalorización de los quesos artesanales mexicanos. Estudios de Ciencias Sociales 19:146-164. 